\title{
Orang Utan Rescue Work in North Sumatra
}

\section{Herman D. Rijksen and Ans G. Rijksen-Graatsma}

Trade in the highly endangered orang utan still goes on despite total protection in its entire range - Indonesia and East Malaysia. The authors spent three years studying orang utans in North Sumatra, trying to get the protection law enforced, and running a rehabilitation station for confiscated animals. The aim was to return the animals to the wild, but the station's real importance was that it made the confiscation of illegally held animals possible, and was thus some deterrent to hunters and traders. Much more damaging than the orang utan trade, however, is the forest destruction that is going on, and it is vital to ensure that large areas of lowland primary forest are preserved from the huge timberlogging operations that are fast destroying the orang utan's habitat.

Orang utans - the mawas - occur in rain forest throughout North Sumatra roughly from $0^{\circ}-5^{\circ} \mathrm{N}$. Since 1931 , they have been protected, but the law has not been enforced, and hunting and trading in orang utans has been widespread. Large numbers have been taken from the Alas Valley, to Medan and shipped abroad. Animals captured in the Langkat Reserve, were exported through Pangkalan Brandan, especially to Japan. On the west side the harbours of Singkil and Tapaktuan were keypoints in a large illegal trade.

Fortunately after 1968 this commercial traffic was greatly reduced by the 1968 agreement between Indonesian conservation authorities and IUCN/SSC, achieved on Barbara Harrisson's initiative, by which no orang utan could be exported from Indonesia without SSC clearance. In 1969 all bona fide zoos in the world agreed not to buy or accept orang utans without this IUCN clearance document. Nevertheless, many orang utans are still brought into captivity. There are many in Indonesian zoos, and others in private hands.

Indonesian zoos have large interests in the orang utan trade. They have international connections with colleagues and traders, and they specialise in acquiring protected and rare Indonesian animals. Possession of a protected species is illegal except under licence; licenced animals may qualify for an export licence later. But, since the number of licences is restricted, and there were no regular checks on stocks, not all animals which qualify under the law became subject to licensing. An orang utan would be acquired to replace one that had died or one that had been moved elsewhere without any record in the Wildlife Department registers.

Most Indonesian zoos are run with little public support and a low government budget; the result is deteriorating animal housing and maintenance, except for those able to profit from licensed exports.

Until about 1966 regular catching operations were organised from villages north of Kutacane (Geumpang, Kongke, Balelutu) by the local Gajo people, who sold the animals to traders in Kutacane; price depended on weight - 1000 $\mathrm{rp} / \mathrm{kg}$ (about US \$2.5). The catching method was to isolate an orang utan in a tree, which was then cut down and the animal caught with bags, ropes etc. Orang utans weighing over $30 \mathrm{~kg}$. were left undisturbed. In 1964, 136 orang utans were sold in Kutacane. 


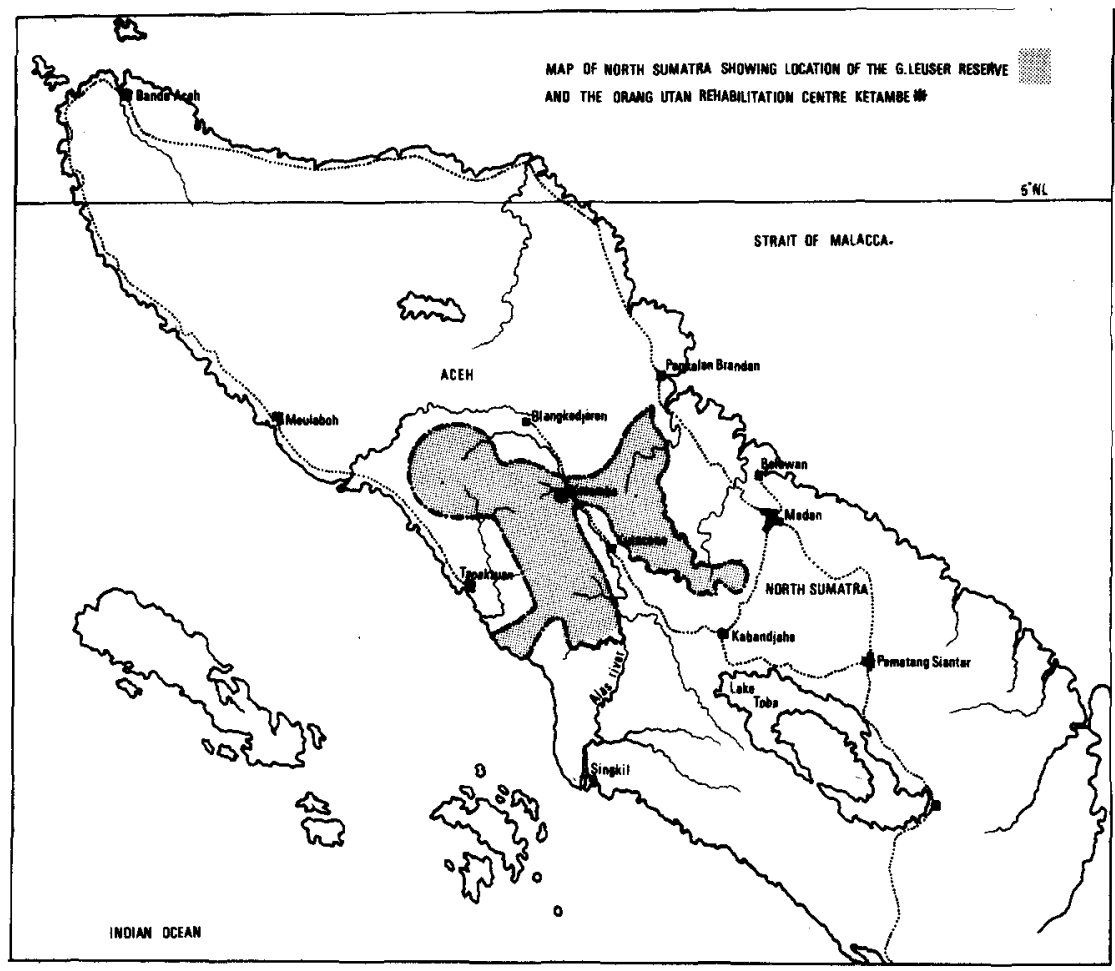

Today, without exception, all young illegally captured orang utans are obtained by killing the mother, usually by shooting; the clinging infant is taken from her body. Even if the youngster remains in the tree, it is easily captured once the mother has been killed. Infants and juveniles always stay close to their mother, and stories of young orang utans captured without their mother being killed can usually be discounted, for example, that the animal was captured when it climbed down a tree to drink from a stream, or that it was damaging crops. Firearms were easily borrowed from soldiers or police, who would be sharing in the profit and who often hunted orang utans themselves. Since 1972 , however, guns can only be carried out of military compounds for training operations.

\section{Captivity}

With the authority and support of the Wildlife and Nature Conservation officials in Medan and Banda Aceh we tried to trace all captive orang utans in North Sumatra and Aceh provinces. Only about half of those we found (28) could be confiscated and taken to the Ketambe Rehabilitation Station, as Table 1 shows; an almost equal number (25) could not be confiscated. Data are based on our two years' residence in the Gunung Leuser Reserves and deal primarily with the Alas Valley, the area most familiar to us. Our sources of information were mostly friends and acquaintances in Medan and Pematang Siantar which we visited about every six weeks; we also made a two-week visit to the west coast and Banda Aceh.* We also kept our eyes open for cages

\footnotetext{
* Since July 1973 a second orang utan Rehabilitation Station has been operating in N. Sumatra (Bohorok, Langkat Reserve) supported by the Frankfurt Zoological Society, and concerned mainly with orang utans on Sumatra's west coast.
} 
Table 1 Orang utans in captivity in North Sumatra and Aceh, June 1971-April 1973

$\begin{array}{lccc}\text { Captured } & \begin{array}{c}\text { Taken to } \\ \text { Rehabilitation } \\ \text { Station }\end{array} & \begin{array}{c}\text { Not taken to } \\ \text { Rehabilitation } \\ \text { Station }\end{array} & \begin{array}{c}\text { Total } \\ \text { captured }\end{array} \\ 1972 & 4 & 4 & \\ 1971 & 10 & 6 & 8 \\ 1970 & 7 & 6 & 16 \\ 1969 \text { and before } & 7 & 9 & 13 \\ & -28 & 25 & 16 \\ & & & 53\end{array}$

and other signs of captive orang utans. We visited the Medan animal market regularly and the zoos in both towns.

Eight young animals were certainly captured in 1972, and it would probably be an underestimate to say that an equal number were captured that year that we did not know about. That makes at least 16 live orang utan babies taken in 1972. And such are the conditions of trade and travel that at least half the captured babies die in transit, which makes three deaths for each one exported: two mothers shot and one baby dying in transit, not to mention the number of unborn lost by killing the adult females. Thus for 1972 an estimated loss to the Sumatra wild population of 64 orang utans can be calculated. In previous years the number has been much higher, but the trade is still large enough to threaten the survival of Sumatra's already much reduced wild population.

\section{Conditions in Captivity}

Captive orang utans are often fed on nothing but plain cooked rice. Even the people who know that an infant needs milk to survive find the price of canned milk powder too high. Because the owners can hope for only a small profit the animals get a minimum of care, resulting in a high mortality. With few exceptions we found the housing was extremely poor, the orang utan being chained or confined to a small cage, crate or box. One adolescent female had been for six years in a cage $1 \frac{1}{2} \times 1 \times 1 \mathrm{~m}$. Another adolescent, now in the Rehabilitation Station, spent its last year, after a six-year stay in a cage, locked in the emptied engine compartment of an old car where it was fed through a small hole.

Several times we met expatriate childless couples who had an orang utan baby as a substitute child; sometimes they had bought complete baby outfits for the animal. One female juvenile was an alcoholic addict when she arrived in the Rehabilitation Station; the former owner, an American bachelor, had enjoyed her company each night at the bar. Another juvenile had her right arm electrocuted when she climbed an electricity pole. Fortunately a German surgeon amputated it in time, and she has adapted well in the Rehabilitation Station. We never found a full adult in captivity. Before reaching this age the animal becomes unmanageable and will be shot at the owner's request by a policeman or a soldier.

Animals kept by local traders in small villages, once they survived the critical infant stage (or if they had been caught after that stage), are often free to move around. They can then find an extra food supply of leaves etc., and 



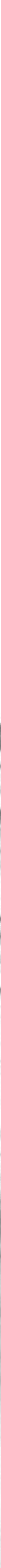




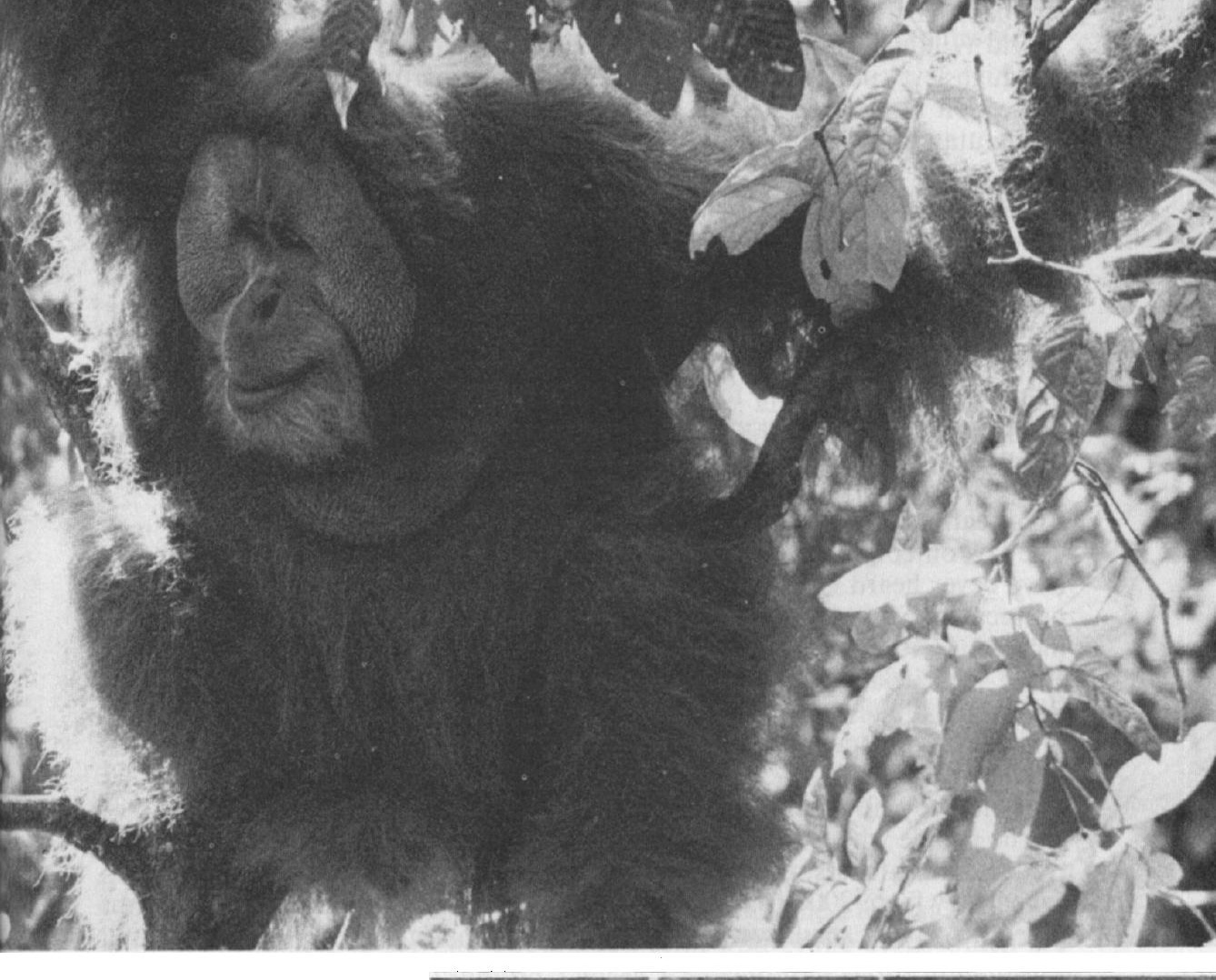


stopped, partly thanks to the efforts of Prince Bernhard, President of the World Wildlife Fund, who, on a visit to Indonesia in 1971, asked the President and high level police and army authorities in Sumatra to enforce the nature protection laws more strictly, especially concerning endangered species like orang utan and rhino.

\section{Station Facilities}

The station, which can only be reached by crossing the Alas river, for which we have two dugouts, has two houses built of local material on the river-bank, one used by one of the Wildlife Officers and two local helpers who are guarding and caring for the animals, the other by the Project Leader.

For the orang utans there is a small quarantine cage near the houses, and a big cage in the primary forest, about $500 \mathrm{~m}$. away, with two compartments - one sleeping/feeding compartment for 1-3-year-old animals, and one for 4-9-year-olds.

\section{Confiscation}

The law on confiscation of illegally kept animals is not strictly enforced. We have never heard of a trader or owner of an illegally kept orang utan being prosecuted. Some owners, faced with confiscation, voluntarily give their animals to the Rehabilitation Station. These are usually wealthy people in urban areas - expatriates, prominent businessmen, or high government officials. Some had bought a miserable sick orang utan out of pity without realising that they were encouraging the trade. People who buy orang utans as pets, paying 5000-10,000 rp. (US $\$ 12.5-25$ ), usually want it as a status symbol or as a nice 'toy' for their children.

The people who want payment for their confiscated orang utan are mostly traders and catchers, probably the ones who supply the private sector. Prices asked vary from $2000 \mathrm{rp}$. (US \$5) to exorbitant sums. Sometimes we did not object to paying small sums in compensation so long as they were too small to stimulate further trade.

It is difficult for the Wildlife Officers to take strong action against these people; their authority to confiscate may be challenged, and though it is becoming difficult to sell orang utans the owners still hope for a little profit, and any money is worth the try. But as long as compensation has to be paid and offenders are not prosecuted, no long-term improvement in the illegal trade can be expected. Only an active programme of immediate confiscation and the animals' return to the forest by way of a rehabilitation station can stop the trade.

\section{Feeding and medical care}

The main aim of the station is to encourage the orang utans to become independent.

The basic diet in the quarantine cage consists of cooked rice, bananas, papayas, and seasonable fruits and vegetables, and milk for the young animals; leaves (papaya and manihot) feature largely. The free-roaming animals are given cooked rice and bananas, which, as orang utans like a varied menu, stimulates them to search for natural food in the forest. Juveniles and adolescents are fed separately, twice a day, in the early morning and in the late afternoon; milk is given at the afternoon feed. 
Animals are not removed from the group for minor ailments; severely sick animals are moved to the quarantine cage. Faeces are examined regularly and worm treatment given when necessary.

\section{Project methods}

Of the 28 animals taken into the station since June 197116 are still there at the time of writing. Their ages range from two to about nine years old. Most had been in captivity for quite a long time, varying from several months to six years. They came from various parts of Aceh and North Sumatra; some were in excellent condition, most in reasonable and a few in very poor condition on arrival.

New arrivals are kept in the isolation cage for conditioning and quarantine, observed for two to three weeks, sometimes more, and then left completely free to go where they want. Only occasionally are they followed for study purposes. The juveniles are locked in at night because of predators; the adolescents mostly prefer to sleep in the nests they have built in the trees near the station.

\section{Predation}

Between April and September 1972 a clouded leopard Neofelis nebulosa gave a lot of trouble and we lost seven orang utans. The leopard never killed outright. It probably attacked the animals on the ground, sometimes in full daylight, so we tried to keep them from coming down to the ground and temporarily locked the young ones in day and night. Finally in September the leopard was caught in a live trap inside the feeding cage.

\section{Tourism}

In the near future the Rehabilitation Station could become a tourist attraction with opportunities to see and photograph semi-wild orang utans which are habituated to people. The Gunung Leuser Reserve area could also be developed for this, but at the moment there is no tourist accommodation and the roads are very poor. Basically tourism and rehabilitation are contradictory. The main aim at the station is to give maximum freedom and a minimum of human contact to these animals which have been very dependent on humans, the young animals particularly seeing humans as substitute mothers. But many tourists like to be photographed with an orang utan, preferably the biggest one, and to touch and play with the animals. So, though we are convinced that tourism can be of great importance for nature conservation in Indonesia, it should be kept in mind that the conservation of the orang utan is the main aim.

\section{Research}

Research is being done on the wild orang utans in the Ketambe research area, by the Nature Conservation Department of the Wageningen Agricultural University, and supported by the Netherlands Foundation for the Advancement of Tropical Research (WOTRO); at the same time comparative ethological and ecological studies are being made of the station's semi-wild orang utans. 


\section{Results}

Of the 28 animals released by the station, three have returned permanently to the forest; an adolescent male not seen since October 1972 can be considered fully rehabilitated; a female juvenile, still very wild when she arrived at the station, returned to the forest soon after her arrival; an adolescent female, which could be regarded as rehabilitated, suddenly became unmanageable and showed signs of aggression against humans. We took her to a part of the reserve separated from the station by a river.

Two others, an adolescent male and an adolescent female, suddenly disappeared, the male for two months, the female for four, both returning in excellent condition. Adolescents do this regularly for periods of up to several weeks. Of the remaining 25 animals, nine have died, seven killed by the clouded leopard and two of malnutrition and diseases shortly after arrival.

The station animals have regular contact with wild orang utans. This is very important, as from them they can learn normal social behaviour. Seven wild animals have visited the station many times, and two, an adult male and an adolescent female, even joined the station-based group for periods of up to several weeks continuously, becoming tolerant of humans, and even accepting food from humans. The station animals regularly go off into the forest with the wild orang utans for some days, and have often been seen feeding in the same tree.

We believe that these contacts will become a continuum, linking the wild and station populations. Contacts with other primates-Hylobates, Symphalangus, Macaca, and Presbytis - have been observed regularly.

\section{Problems}

Inevitably a rehabilitation station such as this has problems.

a. The project animals can pass diseases to the wild population. Orang utans kept in towns and villages, sometimes in very poor conditions and underfed, easily contract diseases. Even after quarantine they may still be carriers or be infected by humans in the station; tbc, hepatitis, polio, and encephalitis can easily move to the wild population.

b. The station might be a potential 'market' for orang utans. It is very hard for local people to understand the project; the forest is still their enemy, and a wild animal something to be killed and eaten, not something to invest money in. They might catch orang utans specially for the station, not for money but to curry favour with the project leader. Rehabilitating orang utans, they feel, must be a hobby of white people and we must want as many animals as possible. They do not understand our dismay at the number of captured orang utans.

\section{Summary and Conclusions}

Catching and trading in orang utans in North Sumatra has diminished in the last few years. Educational and propaganda work by wildlife officers near the Gunung Leuser Reserves, and in Medan and Banda Aceh, have brought awareness of a conservation problem, but it will be a long time before it is generally understood. A market remains, both for local demand and for export. The rehabilitation station was important for starting a confiscation programme.

Rehabilitation seems to be possible in a relatively short time, and the orang 
utans at the station have regular contacts with the wild population. The trade remains a threat, but a far greater threat is the large scale destruction of the primary forest by timberlogging companies, followed by human settlement and shifting cultivation as the population increases. Primary forest is an absolute condition of survival for wild orang utans. If we do not succeed in preserving large areas of lowland primary forest, such as the Gunung Leuser group of reserves, the orang utan will become extinct before the next century.

\section{Acknowledgments}

We would like to acknowledge gratefully the help and assistance given by Mr Walman Sinaga, head Dinas PPA in Bogor, who made it possible for us to work in the Gunung Leuser Reserve and to set up the Rehabilitation Station. We thank Mr Bangun Mulja, kepala seksi Dinas PPA province N. Sumatra, and Mr S. Poniran, kepala seksi Dinas PPA province Aceh, for their assistance in the field and in starting the rehabilitation programme.

We are much indebted to Dr J. H. Westermann and the Netherlands Gunung Leuser Committee for their support and interest and to Professor M. F. Mörzer Bruyns to whom we owe special gratitude for his encouragement and help. The authors' study is financed by a grant from the Netherlands Foundation for the Advancement of Tropical Research (WOTRO).

\section{References}

HARRISSON, B. 1960. Orang utan - What chances of survival ? Sarawak Mus.J. Vol. IX No. $15-16$ pp. $238-261$.

KURT, F. 1970. Final report to IUCN/SSC and WWF International of WWF Project No. 596, Loeser Reserve (Sumatra).

MACKINNON, J. R. 1971. The orang utan in Sabah today. Oryx XI, No. 2-3, pp. 141-191.

MILTON, O. 1964. The orang utan and rhinoceros in North Sumatra. Oryx VII, No. 4, pp. $177-184$.

RIJKSEN, H. D. 1974. Orang utan Conservation and Rehabilitation in Sumatra. Biol. Cons. 6, 1, 20-25.

SILVA, G. S. de 1971. Notes on the Orang utan Rehabilitation Project in Sabah. Malay. Nat.J. 24, pp. $50-77$.

This article was received in August 1973.

\section{Turtles in India}

No sea turtles are protected in India. A report from the Madras Snake Park says many coastal and island towns - in Orissa, Bengal, Kerala, the Andamans and Maldives - have a turtle industry, and wherever there are fishermen near turtle beaches eggs are likely to be harvested. Two Snake Park investigators visited the fish market at Tuticorin, in south India, where every Sunday morning 20-30 sea turtles, mostly green, are killed. Their throats are cut, the blood collected to be drunk; the meat with all fat, guts etc. is sold. Each turtle averages $40-50 \mathrm{~kg}$. of meat. The shell is cut up and sold in lengths. At Tuticorin 1500 turtles are killed every year in this way, mostly for local use. Green turtles are the commonest, but hawksbill, loggerhead, ridley and leatherback also occur and are caught. The report urges that all turtles be given total protection until stocks have increased to the point when a controlled harvest can be taken.

Life on Coral Reefs by Peter Vine, reviewed in Oryx, June 1974, is published by G. T. Phillips and can be obtained from the Seychelles Tourist Office, 202/204 Finchley Road, London NW3, price 72p post paid. 


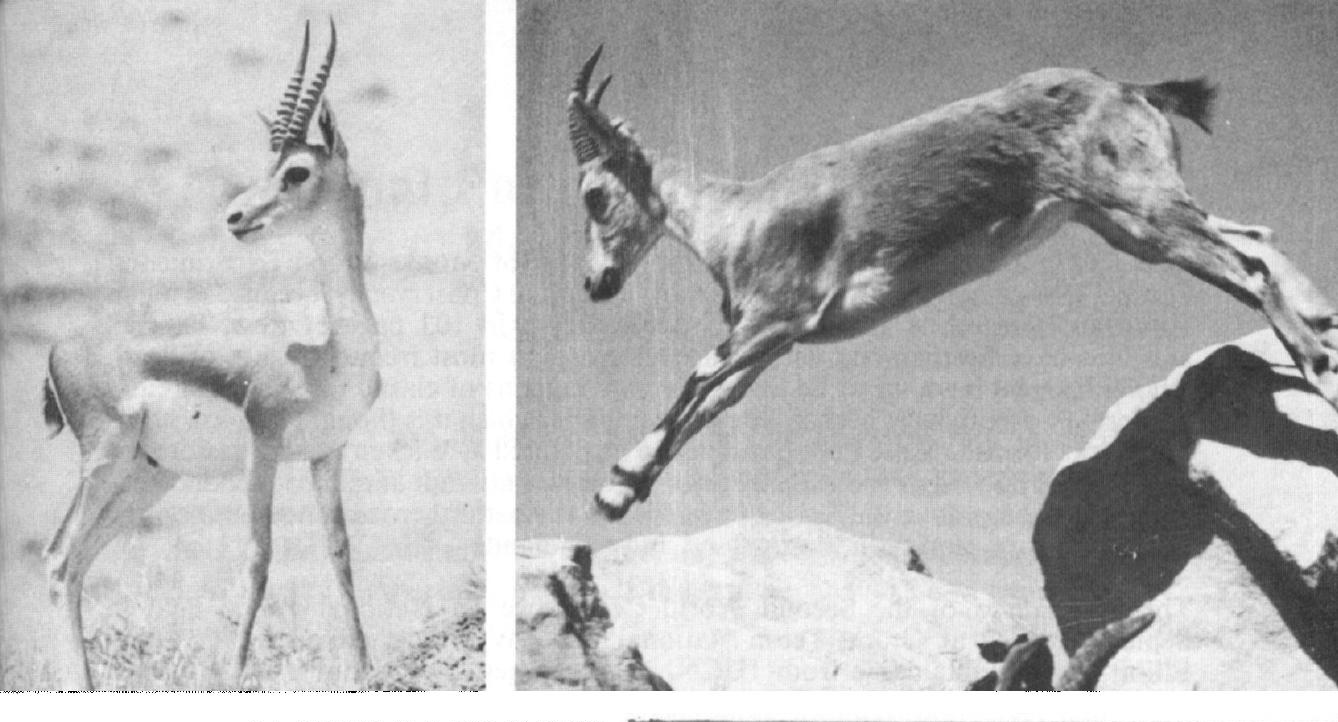

WILDLIFE IN AN ISRAELI RESERVE. The 10,000-acre Hai Bar Nature Reserve in Sinai, 20 miles north of Eilat on the Gulf of Aqaba, was started ten years ago by General Yoffe, Chairman of the Nature Reserves Authority. He aimed to bring back animals mentioned in the Bible that had disappeared, to save from extinction desert species not necessarily native to Israel, such as addax (opposite), scimitarhorned oryx (below), and Somali wild ass (opposite), and to build up populations of animals that had survived in Israel but only precariously, such as the dorcas gazelle and Nubian ibex (above). Over 100 species are now protected in this reserve. The leopard was photographed by the Dead Sea. Very few of this race, Panthera pardus jarvisi, survive in Palestine. This one was lured to a bait.
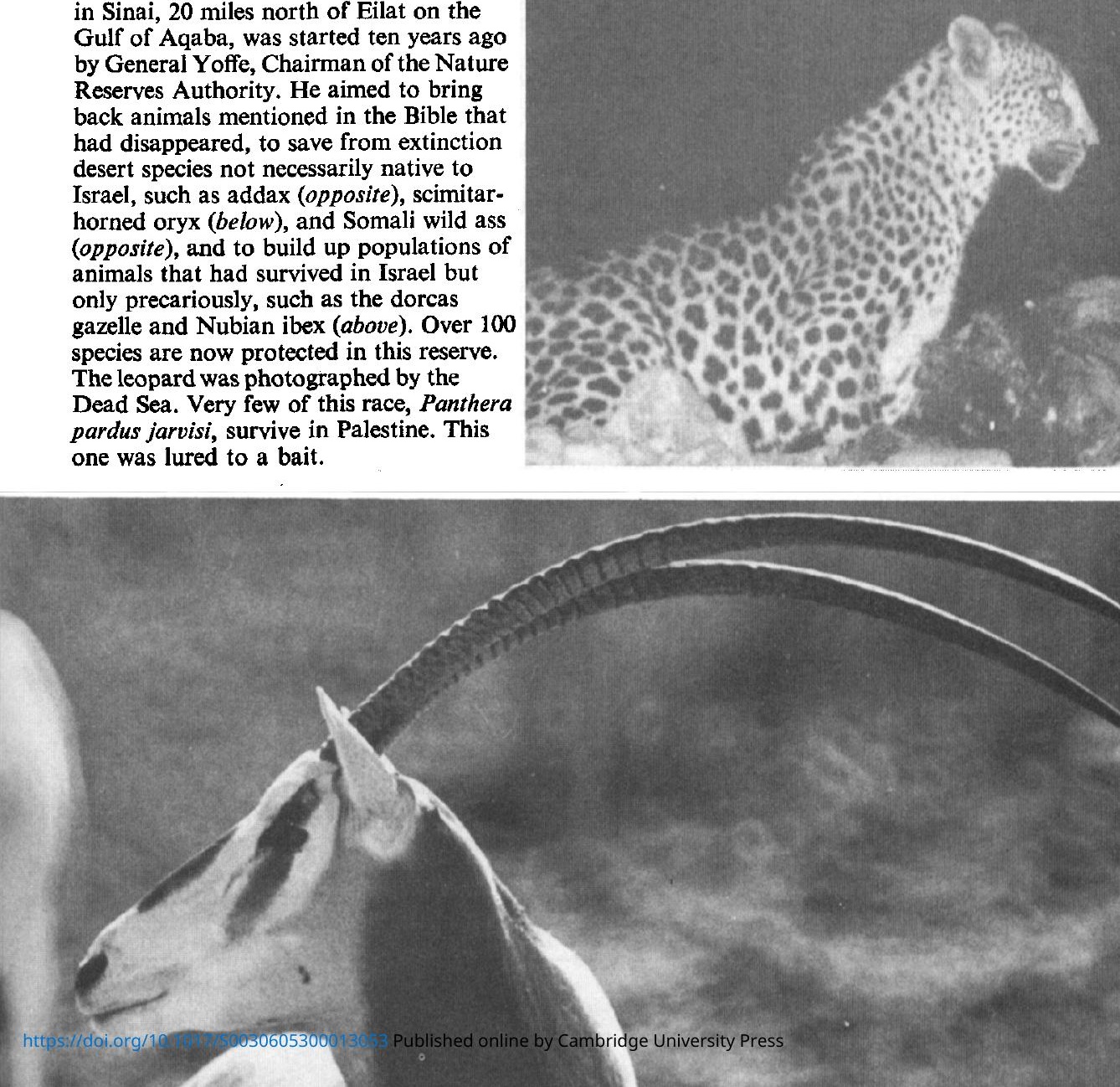